Genet. Sel. Evol. 39 (2007) 431-446

Available online at:

(C) INRA, EDP Sciences, 2007

www.gse-journal.org

DOI: $10.1051 /$ gse:2007013

Original article

\title{
Breeding salmonids for feed efficiency in current fishmeal and future plant-based diet environments
}

\author{
Cheryl D. Quinton ${ }^{\mathrm{a} *}$, Antti KAUSE ${ }^{\mathrm{a}}$, Juha KosKelA ${ }^{\mathrm{b}}$, \\ Ossi Ritola ${ }^{\mathrm{c}}$ \\ ${ }^{a}$ MTT Agrifood Research Finland, Biotechnology and Food Research, Biometrical Genetics, \\ 31600 Jokioinen, Finland

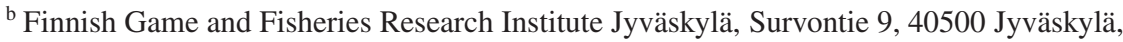 \\ Finland \\ ${ }^{\mathrm{c}}$ Finnish Game and Fisheries Research Institute, Tervo Fisheries Research and Aquaculture, \\ 72210 Tervo, Finland
}

(Received 9 November 2006; accepted 20 January 2007)

\begin{abstract}
The aquaculture industry is increasingly replacing fishmeal in feeds for carnivorous fish with soybean meal (SBM). This diet change presents a potential for genotype-environment $(\mathrm{G} \times \mathrm{E})$ interactions. We tested whether current salmonid breeding programmes that evaluate and select within fishmeal diets also improve growth and efficiency on potential future SBM diets. A total of 1680 European whitefish from 70 families were reared with either fishmeal- or SBM-based diets in a split-family design. Individual daily gain (DG), daily feed intake (DFI) and feed efficiency (FE) were recorded. Traits displayed only weak $\mathrm{G} \times \mathrm{E}$ interactions as variances and heritabilities did not differ substantially between the diets, and cross-diet genetic correlations were near unity. In both diets, DFI exhibited moderate heritability and had very high genetic correlation with DG whereas FE had low heritability. Predicted genetic responses demonstrated that selection to increase DG and FE on the fishmeal diet lead to favourable responses on the SBM diet. Selection for FE based on an index including DG and DFI achieved at least double FE gain versus selection on DG alone. Therefore, current breeding programmes are improving the biological ability of salmonids to use novel plant-based diets, and aiding the aquaculture industry to reduce fishmeal use.
\end{abstract}

feed efficiency / genotype-environment interaction / selection / aquaculture / Coregonus lavaretus

* Corresponding author: cheryl.quinton@mtt.fi 


\section{INTRODUCTION}

The use of fishmeal in aquaculture feeds has become a major issue as the global industry continues to grow [10]. Fishmeal is mostly produced from wild-caught small pelagic fish species, and is considered to be the superior protein source for teleost fishes [18]. It is currently the major component of diets for farmed carnivorous salmonids such as rainbow trout (Oncorhynchus mykiss) and Atlantic salmon (Salmo salar) whose grower diets typically contain 30-50\% fishmeal (2000 statistics [35,45]). However, several environmental and economic reasons exist for reducing fishmeal use. These include the decline and fluctuation of wild stocks harvested for fishmeal production due to overfishing and natural environmental factors, instability and predicted increases in fishmeal prices, and negative consumer perception of the safety of fishmeal-fed products [10,34]. Accordingly, feed manufacturers aim to replace fishmeal with alternatives such as plant products. Soybean meal is one source of protein that can be successfully substituted in part for fishmeal in carnivorous fishes' feeds $[18,23,36,41,43]$. Some major feed companies have pledged to reduce fishmeal use by at least $50 \%$ by 2010 , and it has been predicted that within 10 years, fish diets will be close to $100 \%$ vegetarian [39].

Aquaculture genetic improvement programmes aim to complement such production system changes. Breeding programmes exist for all major farmed carnivorous fish species, and have achieved improvements in growth, feed efficiency, disease resistance and product quality traits [12]. Improved feed efficiency in particular is a goal of most fish breeding programmes, but genetic parameter estimates for feed consumption and efficiency are rare [21, 22, 24,42]. This is because recording methods for individual fish feed intake have only recently been implemented in large-scale genetics research [21, 22, 42]; thus no current breeding programmes select directly for feed efficiency. Furthermore, all breeding programmes evaluate and select broodstock based on performance with current fishmeal-based diets. Future plant-based diets may impact fish breeding programmes if genotype-environment $(\mathrm{G} \times \mathrm{E})$ interactions occur. $\mathrm{G} \times \mathrm{E}$ interactions may occur in the form of genotype re-ranking across environments, or scaling effects as indicated by environmental differences in trait genetic variation $[9,30]$. In a worst-case scenario, superior genotypes on a fishmeal diet would actually be inferior on a plant-based diet. This would be shown by a negative genetic correlation between diets [8]. In this case, current selection on fishmeal diets would compromise performance on future plantbased diets.

In this study, the impact of a novel soybean protein-based diet on selective improvement of growth, feed intake and feed efficiency was investigated in 
European whitefish (Coregonus lavaretus L.), a salmonid now farmed commercially in Finland. A breeding programme has recently been established to improve growth and feed efficiency in this species. To assess the degree to which these traits are affected by $\mathrm{G} \times \mathrm{E}$ interactions when reared with either a traditional fishmeal diet or a potential future soybean meal-based diet, we tested whether these traits express diet-specific phenotypic and genetic variation, and estimated trait genetic correlations between the diets. To quantify the impact of $G \times E$ interaction on selection response, we predicted genetic changes occurring on both diets in response to alternative strategies of selection for growth or feed efficiency on either fishmeal or soybean meal-based diets.

\section{MATERIALS AND METHODS}

\subsection{Diet formulations}

Two practical isonitrogenous and isocaloric diets were formulated (Tab. I). In the fishmeal (FM) diet, fishmeal supplied $100 \%$ of the dietary protein. This diet represents a typical commercial diet used in whitefish farming. In the soybean meal (SBM) diet, $50 \%$ of the dietary protein was replaced with SBMderived protein. This diet represents a realistic future diet. Methionine, lysine and phosphorus supplements were added to the SBM diet to balance these levels with the FM diet. Ingredients were mixed in a Hobart-type mixer, extruded (Clextral BC 45, FR) to $3.5 \mathrm{~mm}$ pellets, re-dried at $40-45^{\circ} \mathrm{C}$, top dressed with fish oil and stored in a freezer until use.

\subsection{Population and experimental design}

Whitefish in the experiment originated from the breeding programme based at the Tervo station of the Finnish Game and Fisheries Research Institute (FGFRI). The original broodstock was established in 1998 by mating 50 wild males and 150 wild females originating from the Kokemäki River, Finland. In October 2003, the generation for the current experiment was established: 45 sires were mated with 52 dams in a partial factorial design to create 70 fulland half-sib families. Each sire was mated to an average of 1.6 dams and each dam to an average of 1.3 sires (both ranges 1-2). Genetic relationships among sires and dams are unknown.

Families were kept separate during incubation and early rearing. At the eyed-egg stage (January 2004), the families were transported to the FGFRI 
Table I. Formulation and analysed nutrient composition of the experimental fishmeal and soybean meal diets.

\begin{tabular}{lcc}
\hline & Fishmeal $\left(\mathrm{g} \cdot \mathrm{kg}^{-1}\right)$ & Soybean meal $\left(\mathrm{g} \cdot \mathrm{kg}^{-1}\right)$ \\
\hline Ingredient & 480 & 255 \\
Fishmeal, capelin $^{\mathrm{a}}$ & 0 & 411 \\
Soybean meal, defatted, hulls $_{\quad}$ removed by sieve $^{\mathrm{a}}$ & & \\
Fish oil, sandeel $^{\mathrm{a}}$ & 160 & 180 \\
Wheat gluten $^{\mathrm{a}}$ & 20 & 20 \\
Wheat meal $^{\mathrm{a}}$ & 267.5 & 34.0 \\
Wheat starch, pregelatinized $^{\mathrm{a}}$ & 52.5 & 52.5 \\
Mono calcium phosphate $^{\mathrm{b}}$ & 0 & 16 \\
L-lysine $^{\mathrm{c}}$ & 0 & 7 \\
DL-methionine $^{\mathrm{d}}$ & 0.0 & 4.5 \\
Vitamin and mineral mix $^{\mathrm{e}}$ & 20 & 20 \\
\hline Analysed composition & & 27 \\
Water $_{\text {Crude protein }}$ & 23 & 404 \\
Crude lipid $_{\text {Crude fibre }}^{\text {N-free extracts }}$ & 398 & 210 \\
Gross energy (MJ $^{\mathrm{f}}$ & 210 & 22 \\
\hline
\end{tabular}

Sources: ${ }^{\text {a }}$ Raisio, FI; ${ }^{\mathrm{b}}$ Kemira, FI; ${ }^{\mathrm{c}}$ BASF, DE; ${ }^{\mathrm{d}}$ Welding GmbH, DE.

e Added to supply (per kg diet): retinol acetate 8000 IU, cholecalciferol 3000 IU, allrace- $\alpha$-tocopheryl acetate $300 \mathrm{IU}$, menadione sodium bisulfite $10 \mathrm{mg}$, thiamine $\mathrm{HCl}$ $21 \mathrm{mg}$, riboflavin $30 \mathrm{mg}$, calcium $d$-pantothenate $92 \mathrm{mg}$, biotin $0.3 \mathrm{mg}$, folic acid $6 \mathrm{mg}$, vitamin $\mathrm{B}_{12} 0.04 \mathrm{mg}$, niacin $120 \mathrm{mg}$, pyridoxine $\mathrm{HCl} 20 \mathrm{mg}$, ascorbic acid (35\% Stay C) $900 \mathrm{mg}$, inositol $200 \mathrm{mg}$, manganese oxide (62\% Mn) $100 \mathrm{mg}$, zinc oxide (74\% Zn) $200 \mathrm{mg}$, potassium iodide (76\% I) $6 \mathrm{mg}$.

${ }^{\mathrm{f}}$ Calculated as $1000-($ water + protein + lipid + fibre $)$.

Laukaa Research Station and incubated (water 4-6 ${ }^{\circ} \mathrm{C}$ ). After hatching (February 2004), 100 to 150 fish per family were held in indoor $150 \mathrm{~L}$ fibreglass tanks (water $13-15^{\circ} \mathrm{C}$ ) and fed commercial dry diets (larvae: AgloNorse, EWOS Ltd., NO; juveniles: Nutra Parr and Royal Silver, Raisio Ltd., FI). In June 2004, approximately 40 random individuals from each family were tagged by injecting a passive integrated transponder into the body cavity. To give all the fish the same initial nutritional environment and to identify if tagging harmed 
any fish, all fish were fed with a 1:1 mixture of the two experimental diets for four weeks prior to the trial.

Twenty-four tagged fish per family were randomly sampled for the diet trial. To construct a split-family design, each family was first randomly split into two groups to be reared with the alternative diets. Each group was evenly distributed over 6 round $0.6 \mathrm{~m}^{3}$ replicate tanks (12 experimental tanks in total). Consequently, the diet trial began with a total of 1680 fish, each tank containing 140 fish (two fish from each family).

The trial was conducted from July 29 to October 21, 2004, during which fish tripled in weight. Fish were fed $6 \mathrm{~h} \cdot \mathrm{d}^{-1}$ using belt feeders. Fish were counted and bulk-weighed biweekly and feeding was adjusted according to average weight and tank biomass. To ensure excess feeding, the feed amounts supplied were adjusted to be 1.3 times higher than predicted by Koskela [27]. Tanks were supplied with fresh water $\left(14.8-15.1{ }^{\circ} \mathrm{C}\right.$; flow rate $8-16 \mathrm{~L} \cdot \mathrm{min}^{-1}$; outlet water $\mathrm{O}_{2}$ level $>80 \%$ saturation) and $24 \mathrm{~h}$ light was provided with ceiling fluorescent tubes. The experimental conditions were standardized to permit accurate comparison of families across diets. This test environment deviates from commercial circumstances where fish are reared in large outdoor net cages under naturally varying environmental conditions.

\subsection{Traits recorded}

Individual body weights were recorded to the nearest $\mathrm{g}$ at the beginning and end of the trial (Tab. II). Daily feed intake was measured by X-radiography [17] 5 times per individual, with 2 -week intervals between measurements. On feed intake measurement days, fish were fed with the same methods and quantity as during normal days, but feed pellets included lead glass beads (Ballotini size 8.5; Jencons Ltd., UK) visible in X-ray. Afterward, fish were anaesthetized, identified, and X-rayed (Bennett HFQ 3000P X-ray machine, US).

To transform the number of glass beads fed to the amount of feed ingested, predictive regression models were established in a separate study. For each diet, 16 samples of known weights were taken from the bead-labelled pellets and X-rayed. The number of beads present in each sample was counted, and diet-specific regression equations were obtained $\left(R^{2}=0.97-0.98\right)$. Feed intake $(\mathrm{g})$ for each individual was predicted using these equations from the number of beads observed under X-ray [17].

Traits analysed were individual daily weight gain (DG), average daily feed intake (DFI) and feed efficiency (FE). Daily gain was calculated as the difference between the initial and the final body weights, divided by the number 
of days in the trial (77-80 d, depending on the tank). Individual DFI was calculated by fitting repeated measures analysis of variance with measurement time (1-5) as the random repeated factor, and then calculating least squares means for each individual (MIXED procedure, SAS ${ }^{\circledR}$ 9.1; SAS ${ }^{\circledR}$ Inst. Inc., US). This was done separately within each experimental tank. Feed efficiency was calculated as the ratio of DG to DFI.

\subsection{Statistical analysis of diet effects}

Diet effects on the means of body weights, DG, DFI and FE were tested with analysis of variance (MIXED procedure). Statistical models included diet as a fixed effect, and replicate tank nested within diet, family, and diet-family interaction as random effects. For all traits, variance due to random experimental tank-family interaction was zero and thus was excluded. Standard errors and degrees of freedom for the $F$-tests of the fixed effects were calculated using the Kenward and Roger option. Additional analyses were performed to standardize DG and DFI to a common body weight by adding initial weight as a regression covariate to the above model.

\subsection{Genetic analysis}

In order to examine $\mathrm{G} \times \mathrm{E}$ interactions, observations recorded under each diet treatment were treated as separate traits. For instance, DG recorded on FM $\left(\mathrm{DG}_{\mathrm{FM}}\right)$ and $\mathrm{SBM}$ diets $\left(\mathrm{DG}_{\mathrm{SBM}}\right)$ were defined as different traits.

Phenotypic and genetic parameters of DG, DFI and FE were estimated using multiple-trait animal models with DMU software, applying restricted maximum likelihood and average information methods [31]. Models contained experimental tank as a fixed effect, and full-sib family, individual genetic and residual error as random effects. The individual genetic effect included additive genetic effects and parts of potential dominance effects. The random full-sib family effect contained (co)variance due to common incubation and early rearing of full sibs, as well as parts of potential dominance (co)variances. Residual covariances between traits measured in different diets were set to zero. Standard errors of (co)variances were obtained by a first-order Taylor series expansion of the average information matrix of the estimated (co)variances. Heritability $\left(h^{2}\right)$ was calculated as the ratio of genetic variance to total phenotypic variance. Full-sib family effect $\left(c^{2}\right)$ was calculated as the ratio of full-sib family variance to total phenotypic variance. When calculating trait correlations within diets, we did not estimate correlations between FE and its component 
traits because this practice can be considered statistically vague due to autocorrelation effects. To aid the reader in perceiving the results, we do however present diet means, variances and heritabilities for FE.

Daily gain and feed intake are commonly expressed relative to body weight. Thus, the analysis for DG and DFI was also carried out using a model that included initial body weight as a covariate. For this study, we use the terms "absolute" and "relative" to refer to traits analysed without and with initial body weight as a covariate, respectively.

\subsection{Prediction of genetic responses to selection}

Selection index calculations were used to predict responses in DG, DFI and FE on both FM and SBM diets to phenotypic selection [15]. Selection was not practiced directly for FE because when selecting on a ratio, genetic changes in the individual component traits are very difficult to control [14]. Four selection strategies were compared: (a) selection for $\mathrm{DG}_{\mathrm{FM}}$; (b) selection for maximum $\mathrm{FE}_{\mathrm{FM}}$ where increased $\mathrm{DG}_{\mathrm{FM}}$ and decreased $\mathrm{DFI}_{\mathrm{FM}}$ were selected for simultaneously and selection index weights were set to obtain maximum genetic change in $\mathrm{FE}_{\mathrm{FM}}$; (c) selection for $\mathrm{DG}_{\mathrm{SBM}}$; and (d) selection for maximum $\mathrm{FE}_{\mathrm{SBM}}$ where increased $\mathrm{DG}_{\mathrm{SBM}}$ and decreased $\mathrm{DFI}_{\mathrm{SBM}}$ were selected to obtain maximum genetic change in $\mathrm{FE}_{\mathrm{SBM}}$. Strategy (a) is comparable to current aquaculture breeding programmes that only select for growth rate. Strategies (c) and (d) predict the effects of selection performed on the potential future soybean diets.

Direct and correlated genetic responses to one generation of selection were

calculated by $\mathbf{R}=\mathrm{i}\left(\mathbf{b}^{\prime} \mathbf{G}\right)\left(\mathbf{b}^{\prime} \mathbf{P b}\right)^{-\frac{1}{2}}$, where $\mathbf{R}$ is the vector of responses, $\mathrm{i}$ is intensity of selection (set to 1 ), $\mathbf{b}$ is the vector of relative index weights which sum to $1, \mathbf{G}$ is the genetic covariance matrix and $\mathbf{P}$ is the phenotypic covariance matrix. $\mathbf{G}$ and $\mathbf{P}$ were results from the 4-trait genetic parameter estimation model for $\mathrm{DG}_{\mathrm{FM}}, \mathrm{DFI}_{\mathrm{FM}}, \mathrm{DG}_{\mathrm{SBM}}$ and $\mathrm{DFI}_{\mathrm{SBM}}$ described above. The parameters for FE were not needed because all results for this ratio can be predicted from its component traits DG and DFI [14].

To generate the alternative selection strategies, relative index weights were modified as follows. To obtain strategy (a), the index weight for $\mathrm{DG}_{\mathrm{FM}}$ was set to 1 , while the weights for the three remaining traits were zero. Similarly, for strategy (c), the index weight for $\mathrm{DG}_{\mathrm{SBM}}$ was set to one. For the selection strategies to maximise FE ( $b$ and d), the maximum genetic response in FE on both diets was obtained when half of the index weight was on DG and half against DFI. 
Table II. Least squares means ( \pm s.e.), and statistical tests for the diet effect for traits recorded on fishmeal and soybean meal diets. Denominator degrees of freedom (ddf) shown; all numerator $\mathrm{df}=1$.

\begin{tabular}{lccccccc}
\hline \multirow{2}{*}{ Trait } & \multicolumn{2}{c}{ Fishmeal } & \multicolumn{3}{c}{ Soybean meal } & \multicolumn{3}{c}{ Test statistics } \\
\cline { 2 - 8 } & $n$ & mean \pm s.e. & $n$ & mean \pm s.e. & ddf & $F$ & $P$ \\
\hline Initial body weight $(\mathrm{g})$ & 818 & $40.9 \pm 0.85$ & 829 & $40.6 \pm 0.87$ & 10.0 & 0.78 & 0.3984 \\
Final body weight $(\mathrm{g})$ & 765 & $131.2 \pm 2.38$ & 768 & $125.8 \pm 2.24$ & 9.7 & 9.36 & 0.0125 \\
Daily gain $\left(\mathrm{g} \cdot \mathrm{d}^{-1}\right)$ & 765 & $1.145 \pm 0.0212$ & 768 & $1.091 \pm 0.0201$ & 9.5 & 20.0 & 0.0014 \\
Daily feed intake $\left(\mathrm{g} \cdot \mathrm{d}^{-1}\right)$ & 817 & $0.948 \pm 0.0236$ & 829 & $1.027 \pm 0.0285$ & 9.6 & 7.23 & 0.0235 \\
Feed efficiency & 765 & $1.208 \pm 0.0150$ & 768 & $1.078 \pm 0.0240$ & 8.5 & 23.2 & 0.0011 \\
\hline
\end{tabular}

To calculate genetic response in FE, mean FE was first calculated for each diet from the data, i.e., before selection. Then, genetic responses to selection were calculated for DG and DFI, and the new mean FE was calculated from these [22].

\section{RESULTS}

\subsection{Diet differences}

As expected, whitefish performed better on the FM diet. Fish fed the FM diet had significantly higher final body weight and DG, lower DFI, and better FE than those fed the SBM diet (Tab. II). These diet differences remained (results not shown) when DG and DFI were standardised by including initial body weight as a covariate $(P<0.0001)$ in the statistical models.

\subsection{Phenotypic and genetic (co)variation}

There was no evidence for diet differences in trait phenotypic or genetic variation. In both diets, DG and DFI showed moderate heritability whereas FE showed very low heritability that did not differ from zero (Tab. III). For a given trait recorded on both diets, the differences in heritabilities between diets were relatively small (mean absolute difference $=0.07$ ) and confidence intervals overlapped considerably. Because heritabilities may remain constant even if the underlying genetic and residual variations change, diet-specific coefficients of variation were also calculated for each trait. Diet differences between coefficients of phenotypic variation for pairs of traits were small (mean absolute difference $=1.1 \%$ ) as well. Coefficients of genetic variation for absolute and relative DG, DFI and FE were only slightly higher on the FM diet (mean difference $=2.9 \%$ ). 
Table III. Phenotypic variance $\left(V_{\mathrm{P}}\right)$, coefficients of genetic $\left(C V_{\mathrm{G}}\right)$ and phenotypic variation $\left(C V_{\mathrm{P}}\right)$, heritability $\left(h^{2} \pm\right.$ s.e. $)$ and full-sib family effect $\left(c^{2} \pm\right.$ s.e. $)$ for absolute and relative (Rel.) traits measured on fish reared with fishmeal and soybean meal diets.

\begin{tabular}{lcrrcc}
\hline Diet, Trait & $V_{\mathrm{P}}$ & $C V_{\mathrm{G}}$ & $C V_{\mathrm{P}}$ & $h^{2} \pm$ s.e. & $c^{2} \pm$ s.e. \\
\hline Fishmeal & & & & & \\
Daily gain & 0.134 & 16.2 & 31.9 & $0.26 \pm 0.18$ & $0.13 \pm 0.09$ \\
Daily feed intake & 0.095 & 15.6 & 32.5 & $0.23 \pm 0.15$ & $0.08 \pm 0.07$ \\
Feed efficiency & 0.044 & 4.3 & 17.4 & $0.06 \pm 0.10$ & $0.04 \pm 0.05$ \\
Rel. daily gain & 0.090 & 17.0 & 26.1 & $0.42 \pm 0.17$ & $0.04 \pm 0.07$ \\
Rel. daily feed intake & 0.068 & 15.6 & 27.6 & $0.32 \pm 0.14$ & $0.03 \pm 0.06$ \\
\hline Soybean meal & & & & & \\
Daily gain & 0.100 & 13.1 & 29.0 & $0.20 \pm 0.15$ & $0.08 \pm 0.08$ \\
Daily feed intake & 0.104 & 12.8 & 31.3 & $0.17 \pm 0.15$ & $0.09 \pm 0.08$ \\
Feed efficiency & 0.033 & 4.3 & 16.9 & $0.07 \pm 0.11$ & $0.07 \pm 0.06$ \\
Rel. daily gain & 0.076 & 14.3 & 25.2 & $0.32 \pm 0.14$ & $0.04 \pm 0.06$ \\
Rel. daily feed intake & 0.081 & 12.6 & 27.8 & $0.21 \pm 0.15$ & $0.10 \pm 0.08$ \\
\hline
\end{tabular}

Genetic correlations between the same traits recorded in each diet indicated very little re-ranking of families across the diets. Genetic correlations ( \pm s.e.) between the diets for DG $(0.97 \pm 0.21)$, DFI $(0.93 \pm 0.28)$ and FE $(1.00 \pm 0.95)$ were all close to unity. The large standard error of the FE correlation was likely caused by the low heritability of this trait. Genetic correlations between the diets for relative DG $(0.99 \pm 0.13)$ and relative DFI $(0.97 \pm 0.22)$ were also very high.

Within-diet trait correlations were similar in both diets. Phenotypic $\left(r_{\mathrm{P}}\right)$ and genetic correlations $\left(r_{\mathrm{G}} \pm\right.$ s.e.) between DG and DFI were high and positive on both FM $\left(r_{\mathrm{P}}=0.88, r_{\mathrm{G}}=0.97 \pm 0.05\right)$ and SBM diets $\left(r_{\mathrm{P}}=0.86, r_{\mathrm{G}}=\right.$ $0.93 \pm 0.10)$. Correlations between relative DG and DFI $\left(\mathrm{FM} r_{\mathrm{P}}=0.82, r_{\mathrm{G}}=\right.$ $0.97 \pm 0.05 ; \mathrm{SBM} r_{\mathrm{P}}=0.82, r_{\mathrm{G}}=0.96 \pm 0.10$ ) were similar to those for absolute traits.

\subsection{Prediction of selection responses}

The selection index calculations showed that current selection on fishmeal diets will lead to strong favourable correlated genetic changes for performance on SBM diets (Fig. 1). Little difference was observed between the diets for genetic response to selection. We emphasize that although the genetic and phenotypic parameter point estimates used in the selection index differed 

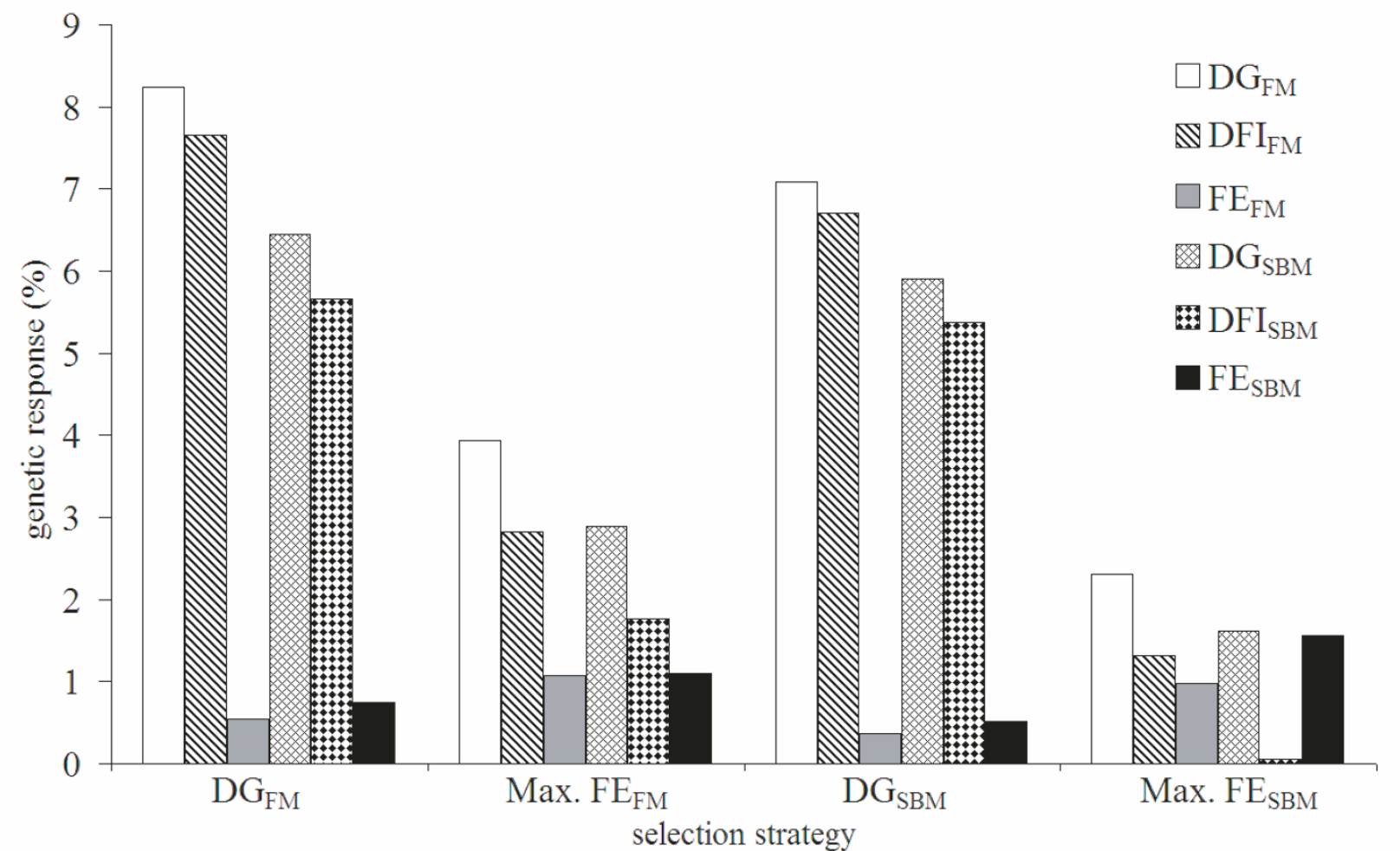

Figure 1. Genetic responses in daily gain (DG), daily feed intake (DFI) and feed efficiency (FE) in fishmeal (FM) and soybean meal (SBM) diets in response to four alternative selection strategies: selection on $\mathrm{DG}_{\mathrm{FM}}$ alone, selection for maximum $\mathrm{FE}_{\mathrm{FM}}$, selection for $\mathrm{DG}_{\mathrm{SBM}}$ alone, and selection for maximum $\mathrm{FE}_{\mathrm{SBM}}$. Genetic responses are given as percent change from the original means in the data. 
slightly between diets, there were overlapping confidence intervals associated with these estimates. Therefore, the genetic responses predicted from the selection index represent average expected differences between the diets and also are subject to variation around the mean.

Selection for $\mathrm{DG}_{\mathrm{FM}}$ caused increased DG and DFI in both diets, and genetic responses on the FM diet were approximately $2.0 \%$ higher than on the SBM diet. In contrast, genetic response in FE was $0.2 \%$ higher on the SBM diet than on the FM diet. Selection for maximum $\mathrm{FE}_{\mathrm{FM}}$ also resulted in genetic responses that differed only slightly between diets; responses for DG and DFI were approximately $1 \%$ higher on the FM diet than on the SBM diet, and FE responses were similar across diets (Fig. 1).

Direct selection for $\mathrm{DG}_{\mathrm{SBM}}$ or maximum $\mathrm{FE}_{\mathrm{SBM}}$ did not generally achieve better genetic responses in SBM traits than the correlated responses obtained by selection on the respective FM traits (Fig. 1). Genetic responses in $\mathrm{DG}_{\mathrm{SBM}}$ and $\mathrm{FE}_{\mathrm{SBM}}$ were $0.5 \%$ and $0.2 \%$ higher, respectively, in the $\mathrm{DG}_{\mathrm{FM}}$ selection strategy than in the $\mathrm{DG}_{\mathrm{SBM}}$ strategy. However, genetic response in $\mathrm{FE}_{\mathrm{SBM}}$ was $0.46 \%$ higher in the maximum $\mathrm{FE}_{\mathrm{SBM}}$ strategy than in the $\mathrm{FE}_{\mathrm{FM}}$ strategy.

Compared with the DG selection strategies, the maximum $\mathrm{FE}_{\mathrm{FM}}$ and $\mathrm{FE}_{\mathrm{SBM}}$ strategies doubled the genetic response in $\mathrm{FE}_{\mathrm{FM}}$, and tripled the $\mathrm{FE}_{\mathrm{SBM}}$ response, respectively (Fig. 1). However, the FE strategies also caused approximately $4 \%$ lower responses in DG compared to DG strategies.

\section{DISCUSSION}

\subsection{Impacts of $\mathbf{G} \times \mathbf{E}$ on breeding programmes}

In the current study, only weak diet $\mathrm{G} \times \mathrm{E}$ interactions were detected for growth, feed intake and feed efficiency in European whitefish. Therefore, increased soybean meal (SBM) use in feeds does not compromise the genetic improvements achieved by breeding programmes. In effect, results from selection index calculations show that current fish breeding programmes that select on fishmeal diet (FM) growth or feed efficiency performance also improve their broodstock's ability to use novel soybean meal diets.

Furthermore, this study confirms that the current fishmeal diet is an appropriate environment for evaluating and selecting genotypes for improved growth and efficiency on future soybean meal-based diets. Direct selection for FM growth was as effective for improving SBM diet growth and feed efficiency as direct selection for SBM growth. The only situation in which the SBM diet was a superior selection environment was for direct selection for SBM diet 
feed efficiency. Breeding programmes operating within future diet environments should therefore achieve genetic gains comparable to those with current diets.

These results are a consequence of two factors. First, trait heritabilities and phenotypic variations did not differ substantially across diets. Although several studies have shown $\mathrm{G} \times \mathrm{E}$ interaction expressed by elevated genetic variation in stressful or novel conditions [6], this did not occur in our study. Modern SBM products are well processed and thus may only cause mild environmental stress in salmonids. Second, genetic correlations for DG, DFI and FE between diets were close to unity, indicating little re-ranking of families across the diets. These weak re-rankings agree with other farmed fish studies that have found little or no family interactions with diet nutrient levels [1,2, 13, 22, 37] or production environments [20,44].

Although novel soybean meal feeds should not be problematic for selective breeding of whitefish, novel high soy diets can cause reduced growth and feed efficiency in salmonids (e.g., $[4,40])$. In the current study, the SBM diet supported slower growth but higher feed intake which indicate that it was digested or processed less well than the FM diet, probably due to anti-nutritional factors present in soybean meal [11] for which whitefish are not adapted. Major efforts around the world are refining plant-protein based fish feeds through ingredient selection, supplementation and processing techniques [11]. Our results show that selective breeding is an effective complementary method to improve biological utilization of novel feed ingredients by farmed fish.

\subsection{Genetic improvement of feed efficiency}

Our results show that genetic improvement of feed efficiency for both fishmeal and soybean meal based diets can be achieved through selection in European whitefish. Simultaneous selection for fast growth and reduced feed intake achieved at least double the genetic response in feed efficiency versus selection on growth alone.

However, genetic progress in feed efficiency occurs slowly; the greatest predicted selection responses in FE were 7-8 times smaller than gains achieved in growth rate. Accordingly, the heritability for FE was low (0.06-0.07). This was unexpected because in terrestrial farm animals the average heritability of FE is moderate, 0.25 , and has similar magnitude as for growth traits [38]. The only known previous estimates of efficiency heritability in fish ( 0.3 in rainbow trout [24]) are also higher than in our data, however those were based on family means and thus represent overestimates. In our data, feed intake 
exhibited moderate heritability $(0.17-0.32)$ that is typical of feed consumption traits in terrestrial species (e.g., 0.25 [5], 0.23 [19]) and midway between previous estimates for rainbow trout (average 0.10 [22]) and catfish Ictalurus punctatus (0.41 [42]).

In terrestrial animals, improvement of feed efficiency has been attributed to lowered maintenance energy requirements through endocrine changes [28] and reduced thermogenesis, physical activity [29,33] and protein turnover rates [32]. We hypothesize that cultured salmonids can display very low FE heritability for two reasons. First, maintenance or resting metabolism rates of poikilothermic fish are 10 to 30 times less than mammals and up to 100 times less than birds of the same weight [3]. Thus, potential variation in maintenance requirements generates very little genetic variation for FE in fish. Second, because FE studies in salmonids are usually conducted during an exponential growth phase, most feed consumed is directed to growth, and there is very little variation in nutrient diversion to other body functions. These contribute to an almost unity correlation between feed intake and growth that reduces variation in FE. Genetic correlations between daily gain and feed intake in both European whitefish $(0.93,0.97$; this study) and rainbow trout (0.86-0.96 [22]) were very high. In contrast, in terrestrial animals this correlation is typically lower $(0.6-0.7[5,7,26])$.

At this time, no known fish breeding programmes select directly for feed efficiency; all rely on a correlated genetic response obtained by sole selection for high body weight. Previous studies have proposed that feed efficiency in fish can be indirectly improved by selection for fast growth $[16,24,25]$. The selection index results in the current study also support the effectiveness of selection for growth as a strategy to indirectly improve efficiency. However, simultaneous selection for fast growth and reduced feed intake achieved at least double the genetic response in feed efficiency versus selection on growth alone. Although the increase in feed efficiency generated by including feed intake to the selection index was small $(<2 \%)$, on a production scale such improvements translate to considerable economic benefits [25] and therefore may merit the measurement expense in a selective breeding programme.

\section{ACKNOWLEDGEMENTS}

The authors thank M. Henryon and two anonymous referees for constructive comments on early versions of this manuscript. The study was funded by the Employment and Economic Development Centre of Central Finland. 


\section{REFERENCES}

[1] Austreng E., Refstie T., Effect of varying dietary protein level in different families of rainbow trout, Aquaculture 18 (1979) 145-156.

[2] Austreng E., Risa S., Edwards D.J., Hvidsten H., Carbohydrate in rainbow trout diets. II. Influence of carbohydrate levels on chemical composition and feed utilization of fish from different families, Aquaculture 11 (1977) 39-50.

[3] Brett J.R., The metabolic demand for oxygen in fish, particularly salmonids, and a comparison with other vertebrates, Respir. Physiol. 14 (1972) 151-170.

[4] Bureau D.P., Harris A.M., Cho C.Y., The effects of purified alcohol extracts from soy products on feed intake and growth of chinook salmon (Oncorhynchus tshawytscha) and rainbow trout (Oncorhynchus mykiss), Aquaculture 161 (1998) 27-43.

[5] Cammack K.M., Leymaster K.A., Jenkins T.G., Nielsen M.K., Estimates of genetic parameters for feed intake, feeding behavior, and daily gain in composite ram lambs, J. Anim. Sci. 83 (2005) 777-785.

[6] Charmantier A., Garant D., Environmental quality and evolutionary potential: lessons from wild populations, Proc. R. Soc. B 272 (2005) 1415-1425.

[7] Clutter A.C., Brascamp E.W., Genetics of performance traits, in: Rothschild M.F., Ruvinsky A. (Eds.), The Genetics of the Pig, CAB International, Wallingford, 1998, pp. 427-462.

[8] Falconer D.S., The problem of environment and selection, Am. Nat. 86 (1952) 293-298.

[9] Falconer D.S., Mackay T.F.C., Introduction to quantitative genetics, 4th edn., Longman, Essex, 1996.

[10] FAO Fisheries Department, The state of world fisheries and aquaculture (SOFIA) 2004, Food and Agriculture Organization of the United Nations, Rome, 2004.

[11] Francis G., Makkar H.P.S., Becker K., Antinutritional factors present in plantderived alternate fish feed ingredients and their effects in fish, Aquaculture 199 (2001) 197-227.

[12] Gjedrem T., Thodesen J., Selection, in: Gjedrem T. (Ed.), Selection and Breeding Programs in Aquaculture, Springer, Dordrecht, 2005, pp. 89-111.

[13] Glover K.A., Taggart J.B., Skaala O., Teale A.J., A study of inadvertent domestication selection during start-feeding of brown trout families, J. Fish Biol. 64 (2004) 1168-1178.

[14] Gunsett F.C., Linear index selection to improve traits defined as ratios, J. Anim. Sci. 59 (1984) 1185-1193.

[15] Hazel L.N, The genetic basis for constructing selection indexes, Genetics 28 (1943) 476-490.

[16] Henryon M., Jokumsen A., Berg P., Lund I., Pedersen P.B., Olesen N.J., Slierendrecht W.J., Genetic variation for growth rate, feed conversion efficiency, and disease resistance exists within a farmed population of rainbow trout, Aquaculture 209 (2002) 59-76.

[17] Jobling M., Coves D., Damsgård B., Kristiansen H.R., Koskela J., Petursdottir T.E., Kadri S., Gudmundsson O., Techniques for measuring feed intake, 
in: Houlihan D., Boujard T., Jobling M. (Eds.), Food Intake in Fish, Blackwell Science Inc., Oxford, 2001, pp. 49-87.

[18] Jobling M., Gomes E., Dias J., Feed types, manufacture and ingredients, in: Houlihan D., Boujard T., Jobling M. (Eds.), Food Intake in Fish, Blackwell Science Inc., Oxford, 2001, pp. 25-48.

[19] Johnson Z.B., Chewning J.J., Nugent R.A. III, Genetic parameters for production traits and measures of residual feed intake in large white swine, Anim. Sci. 77 (1999) 1679-1685.

[20] Kause A., Ritola O., Paananen T., Breeding for improved appearance of large rainbow trout in two production environments, Aquacult. Res. 35 (2004) 924-930.

[21] Kause A., Tobin D., Dobly A., Houlihan D., Martin S., Mäntysaari E.A., Ritola O., Ruohonen K., Recording strategies and selection potential of feed intake measured using the X-ray method in rainbow trout, Genet. Sel. Evol. 38 (2006) 389-409.

[22] Kause A., Tobin D., Houlihan D.F., Martin S.A.M., Mäntysaari E.A., Ritola O., Ruohonen K., Feed efficiency of rainbow trout can be improved through selection: Different genetic potential on alternative diets, J. Anim. Sci. 84 (2006) 807-817.

[23] Kaushik S.J., Cravedi J.P., Lalles J.P., Sumpter J., Fauconneau B., Laroche M., Partial or total replacement of fish meal by soybean protein on growth, protein utilization, potential estrogenic or antigenic effects, cholesterolemia and flesh quality in rainbow trout, Oncorhynchus mykiss, Aquaculture 133 (1995) 257-274.

[24] Kinghorn B., Genetic variation in food conversion efficiency and growth in rainbow trout, Aquaculture 32 (1983) 141-155.

[25] Kolstad K., Grisdale-Helland B., Gjerde B., Family differences in feed efficiency in Atlantic salmon (Salmo salar), Aquaculture 241 (2004) 169-177.

[26] Koots K.R., Gibson J.P., Smith C., Wilton J.W., Analyses of published genetic parameter estimates for beef production traits, 1. Heritability, Anim. Breed. Abstr. 62 (1994) 309-338.

[27] Koskela J., Growth rate and feeding level of European whitefish (Coregonus lavaretus L. s.l.) under hatchery conditions, Pol. Arch. Hydrobiol. 39 (1992) 731-738.

[28] Luiting P., The role of genetic variation in feed intake and its physiological aspects: results from selection experiments, in: van der Heide D., Huisman E.A., Kanis E., Osse J.W.M., Verstegen M.W.A. (Eds.), Regulation of Feed Intake, CAB International, Wallingford, 1999, pp. 75-87.

[29] Luiting P., Schrama J.W., van der Hel W., Urff E.M., Metabolic differences between White Leghorns selected for high and low residual food consumption, Brit. Poult. Sci. 32 (1991) 763-782.

[30] Lynch M., Walsh B., Genetics and analysis of quantitative traits, Sinauer Associates, Sunderland, 1998.

[31] Madsen P., Jensen J., A user's guide to DMU, a package for analysing multivariate mixed models, Danish Institute of Agricultural Sciences, Tjele, 2006. 
[32] McDonagh M.B., Herd R.M., Richardson E.C., Oddy V.H., Archer J.A., Arthur P.F., Meat quality and the calpain system of feedlot steers following a single generation of divergent selection for residual feed intake, Aust. J. Exp. Agric. 41 (2001) 1013-1021.

[33] McPhee C.P., Kerr J.C., Cameron N.D., Peri-partum posture and behaviour of gilts and the location of their piglets in lines selected for components of efficient lean growth, Appl. Anim. Behav. Sci. 71 (2001) 1-12.

[34] Naylor R.L., Goldburg R.J., Primavera J.H., Kautsky N., Beveridge M.C.M., Clay J., Folke C., Lubchenco J., Mooney H., Troel M., Effect of aquaculture on world fish supplies, Nature 405 (2000) 1017-1024.

[35] New M.B., Wijkström U.N., Use of fishmeal and fish oil in aquafeeds: further thoughts on the fishmeal trap, FAO Fisheries Circular C975, Food and Agriculture Organization of the United Nations, Rome, 2002.

[36] Olli I.J., Krogdahl Å., Nutritive value of four soybean products in diets for rainbow trout (Oncorhynchus mykiss, Walbaum) reared in fresh water, Acta Agric. Scand. A 44 (1994) 185-192.

[37] Palti Y., Silverstein J.T., Wieman H., Phillips J.G., Barrows F.T., Parsons J. E., Evaluation of family growth response to fishmeal and gluten-based diets in rainbow trout (Oncorhynchus mykiss), Aquaculture 255 (2006) 548-556.

[38] Pitchford W.S., Genetic improvement of feed efficiency of beef cattle: what lessons can be learnt from other species? Aust. J. Exp. Agricult. 44 (2004) 371-382.

[39] Powell K., Fish farming: Eat your veg, Nature 426 (2003) 378-379.

[40] Refstie S., Storebakken T., Roem A.J., Feed consumption and conversion in Atlantic salmon (Salmo salar) fed diets with fish meal, extracted soybean meal or soybean meal with reduced content of oligosaccharides, trypsin inhibitors, lectins and soya antigens, Aquaculture 162 (1998) 301-312.

[41] Refstie S., Storebakken T., Baeverfjord G., Roem A.J., Long-term protein and lipid growth of Atlantic salmon (Salmo salar) fed diets with partial replacement of fish meal by soy protein products at medium or high lipid level, Aquaculture 193 (2001) 91-106.

[42] Silverstein J.T., Bosworth B.G., Waldbieser G.C., Wolters W.R., Feed intake in channel catfish: is there a genetic component? Aquacult. Res. 32 s1 (2001) 199-205.

[43] Storebakken T., Refstie S., Ruyter B., Soy products as fat and protein sources in fish feeds for intensive aquaculture, in: Drackley J.K. (Ed.), Soy in Animal Nutrition, Federation of Animal Science Societies, Savoy, 2000, pp. 127-170.

[44] Sylvén S., Rye M., Simianer H., Interaction of genotype with production system for slaughter weight in rainbow trout (Oncorhynchus mykiss), Livest. Prod. Sci. 28 (1991) 253-263.

[45] Tacon A.G.J., Use of fish meal and fish oil in aquaculture: a global perspective, Aquat. Resour. Cult. Dev. 1 (2004) 3-14. 